\title{
Numerical Analysis of Rainfall Saturated-Unsaturated Seepage and Stability of Expansive Soil Slope with Fissures
}

\author{
Hou Dinggui, Tao Zhigang *, Hao Zhenli, Wang Jiamin \\ State Key Lab. For Geo-mechanics and Deep Underground Engineering, School of Mechanics and Civil Engineering, \\ China University of Mining \& Technology, Beijing, \\ D11 Xueyuan Road, Haidian District, Beijing, China \\ houdinggui@126.com, 33251816@qq.com, 729598707@qq.com,626102804@qq.com
}

\begin{abstract}
The existence of fissures is an important factor in expansive soil slope landslide under rainfall conditions. In order to explore the changes characteristic of expansive soil slope seepage field and its stability under rainfall conditions, considering the fissures, the finite element numerical simulation of saturated unsaturated seepage in expansive soil slope under rainfall is carried out, obtaining the time and space distribution of pore water pressure and transient saturation area. Then import the analysis results into FLAC3D software which based on the finite difference method, finally assignment of physical and mechanical parameters in saturated unsaturated, this achieves stability analysis under the presence of fissures, and also reflects the water softening influence on the stability of expansive soil slope. Through the example analysis shows that, the existence of fissures in expansive soil slope has remarkable influence the rainfall infiltration and pore water pressure distribution, the numerical simulation study conclusions are consistent with the existing results, it is proved that this method is effective and practical, the research findings have certain reference significance of the analysis of slope stability and its saturated unsaturated seepage.
\end{abstract}

Keywords-fissures; rainfall; seepage; stability; numerical analysis

\section{INTRODUCTION}

Expansive soils are widely distributed and for the construction of a special hazardous soil. It mainly consists of strongly hydrophilic mineral composition montmorillonite and illite, with the inflatable structure and multiple fractures strong expansion and contraction and strength attenuations of high plasticity clay soil [1]. Expansive soil slope instability occurs after heavy rains, landslide survey shows that rainfall and the rain infiltration are the main external cause of expansive soil slope instability [2]. The mechanism of expansive soil landslide: More expansive soil slope in the saturated and unsaturated state, under the effect of external climate, the soil surface evaporation, the formation of drying shrinkage fissures. The existence of fissures results in a loss of integrity of soil, the decrease of strength of expansive soil, extremely easily lead to the rain infiltration. Under the condition of rainfall, the rainfall will cause surface soil pore water pressure rises, the negative pore water pressure that matrix suction decreases, density increases, and reduce the strength of the soil water, easily lead to slope instability [3].

Currently considering fissure expansive soils saturated and unsaturated seepage and stability analysis of a certain research results, but this slope stability analysis method which uses mostly limit equilibrium method, there are some insufficient in the calculation results [4-8]. In this paper, considering the fissure of analysis on the basis of expansive soil seepage field, the pore water pressure and the space-time distribution of transient saturated zone analysis results import FLAC3D numerical simulation software, and combined with saturated and unsaturated soil physical mechanics parameter analysis, has realized the fissure in the presence of expansive soil slope seepage field numerical simulation with finite difference method based on the slope stability analysis, at the same time reflects the soil water softening factor's influence on the slope stability.

\section{Numerical Simulation OF SEEPAGE}

\section{A. Calculation Principle}

In the slope stability analysis, when the water table is a shallow burial, the groundwater movement of soil water movement in the unsaturated region and saturated region is connected with each other, then unify the two research is more convenient, the so called saturated-unsaturated flow issue. The pressure head $h$ can be regarded as control equation of dependent variable in this case. For considering permeability anisotropy of two-dimensional saturated unsaturated flow problems, when the coordinate orientation and large, consistent with the main direction of the small penetration, seepage control equation is:

$$
\frac{\partial}{\partial_{x}}\left(k_{x} \frac{\partial h}{\partial x}\right)+\frac{\partial}{\partial_{z}}\left(k_{z} \frac{\partial h}{\partial z}\right)+\frac{\partial k_{z}}{\partial z}=c(h) \frac{\partial h}{\partial t}
$$

Where: $\mathrm{k}_{\mathrm{x}}$, $\mathrm{k}_{\mathrm{z}}$ respectively represents soil level and vertical permeability; $h$ is pressure head; $c(h)$ is bulk density than water. In this paper, using the finite element method to solve the equation of two-dimensional seepage questions. There are two types of boundary conditions: 
1) Head Boundary Known:

$$
h\left(x_{1}, y_{1}, t\right)=h_{b}\left(x_{1}, y_{1}, t\right)
$$

In the formula $h_{b}\left(x_{1}, y_{1}, t\right)$ is fixed values of pressure head.

2) Flow Boundary Conditions Are Known:

$$
k_{i j}(h) \frac{\partial h}{\partial x_{j}} n_{i}=-f\left(x_{i}, t\right)
$$

In the formula $n_{i}$ is the unit normal vector of the boundary surface; $f$ is the normal flow.

\section{B. Boundary Conditions}

According to the relationship between rainfall intensity and soil permeability, the boundary conditions of unsaturated seepage questions can have a variety of forms. Surface and slope boundary conditions is set to pressure head or flow, when the rain stronger than the permeability of soil, using constant head boundary conditions, otherwise the flow boundary conditions is used, model on both sides of the ground water level surface above zero set to flow boundary, under the water surface is set to constant head boundary, the bottom is set to impervious boundary.

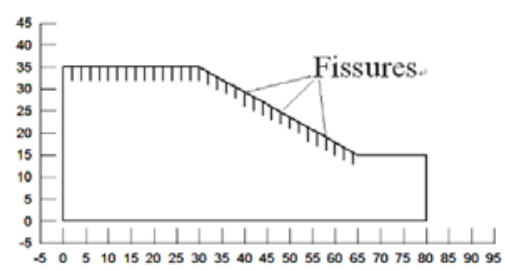

(a) geometric model with fissures.

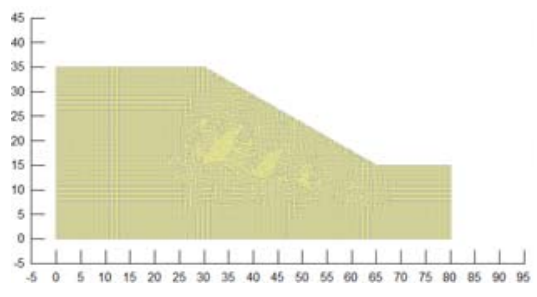

(b) mesh of finite element method.

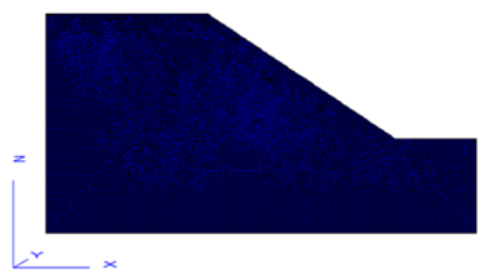

(c) mesh of finite difference numerical method.

Fig. 1. Analysis model.
Fissure is directly set along the corresponding unit boundary with certain seepage boundary conditions; rainfall infiltration will be along the edge of the unit to permeate the soil on both sides of the unit as shown in Fig. 1a. The methods full consider the seepage characteristics of expansive soil with fissure, which can well describe the rainfall infiltration of expansive soil.

\section{Calculation Model}

Take JiHui expansive soil slope engineering project in the yanbian area as an example, the finite element, and finite difference methods were used to analysis the changes of seepage field and stability caused by rainfall infiltration. The Finite element grid subdivision is shown as Fig. 1b, in which the unit number is 8655 , the node number is 8762 .

Initial condition in the left side of the border is set to fifteen meters head, the water level on the right side of the border slope seven meters head.

\section{Calculated Parameters}

Based on the field test, the curve of volatile water content, negative pore water pressure, a curve of conductivity, and negative pore water pressure for computing is shown in Fig. 2a and Fig. 2b.

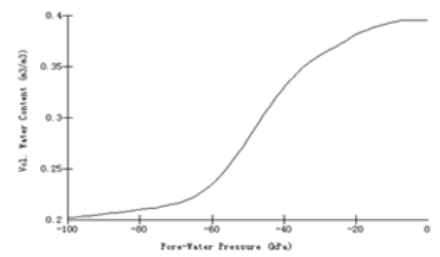

(a) curve of volatile water content and negativepore water pressure.

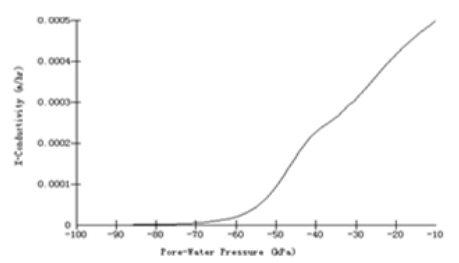

(b) curve of conductivity and negativepore water pressure

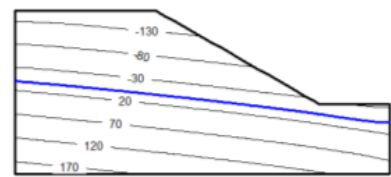

(c) contour of initial pore water pressure.

Fig. 2. Seepage calculation function and initial seepage field. 


\section{E. Calculation Scheme and Results}

According to local rainfall characteristics, rainfall intensity is $3 \mathrm{~mm} / \mathrm{hr}$, the computing time and rainfall duration are $72 \mathrm{hr}$, computing time step for $1 \mathrm{hr}$. Saturated permeability coefficient is $0.5 \mathrm{~mm} / \mathrm{hr}$; fissure depth is 3 meters.

Due to rainfall infiltration is close to the initial seepage field, therefore, first of all, solving a steady seepage field as rainfall transient analysis of the initial conditions, the contour of initial seepage field as shown in Fig. 2c.

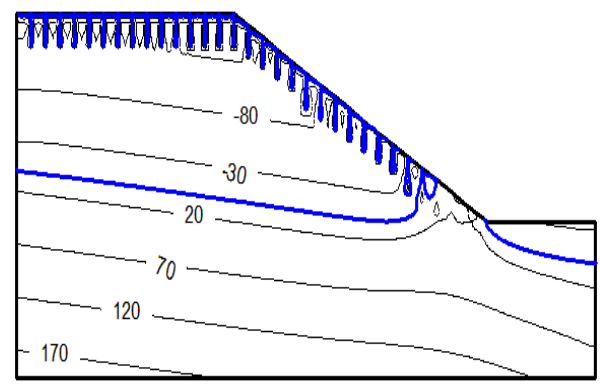

(a) 24 hours time

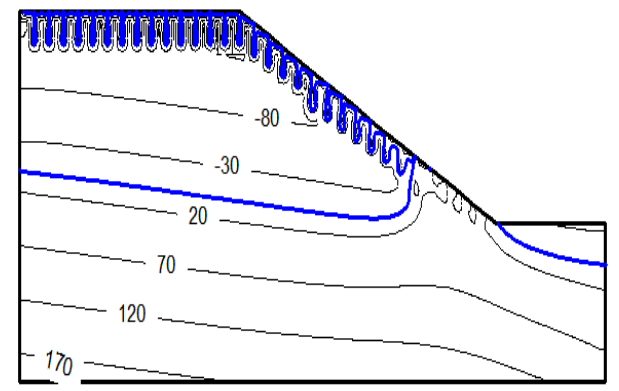

(b) 48 hours time.

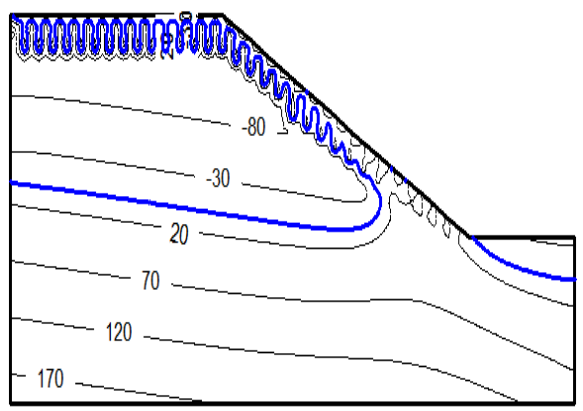

(c) 72 hours time (unit: $\mathrm{kPa}$ ).

Fig. 3. Contours of pore water pressure.

As shown in Fig. 3, considering fissures of the slope under the condition of seepage, fissures of rainfall infiltration in the slope have a significant impact on seepage field. First of all, by a lot of soil infiltration of the fissure, and quickly form a transient saturated zone near the fissure, pore water pressure first appear in the fissure, early rainfall infiltration is mainly change the pore water pressure by fissure, and matrix suction is almost no loss where outside fissures influence depth. As rainfall and infiltration of other parts of the slope surface rain continued relatively slow infiltration, pore water pressure changes present integrity, transient saturated zone of slope surface is gradually expanding, slope water level gradually rising.

\section{STABILITy ANALYSIS OF EXPANSIVE SOIL SLOPE}

The finite difference numerical method is based on FLAC3D analyses typical section that the establishment of quasi three dimensional equivalent models is based on a twodimensional grid. The model of grid computing unit is 8655 and the node is 17524 . Fig. 1c is the numerical grid graph. Horizontal displacement constraint boundary condition is applied in the model left and right sides, at the same time, the vertical displacement constraint conditions is applied in the bottom edge of the model.

In the area of strength test method of main indexes are natural quick shear, shear and saturated quickly consolidated quick shear, slow shear etc. Mechanical indexes of saturated and unsaturated are strength as shown in Table I.

TABLE I. MECHANICS PARAMETER OF EXPANSIVE SOIL

\begin{tabular}{|c|c|c|}
\hline Mechanical & Unsaturated state & Saturated state \\
\hline Modulus elasticity/MPa & 100 & 100 \\
\hline Poisson's ratio & 0.32 & 0.32 \\
\hline Density/g.cm & \\
\hline Cohesive force/kPa & 2.1 & 2.3 \\
\hline Angle of friction/( ${ }^{\circ}$ & 30 & 15 \\
\hline
\end{tabular}

Initial geostress field will be considered by the self-weight stress field for the accuracy of simulating the effect of rock parameters on slope stability. First of all, using the elastic model is analyzed, and then the calculation of displacement in the model and reserving unit stress. Finally, the seepage computational grid node information is imported (Pore water pressure). Fig. 4 is a diagram of pore water pressure distribution which has imported pore water pressure.

The mechanics parameters of the rock-soil body below the underground water level and transient saturated zone are considered by unsaturated soil strength parameters. The underground water level is above according to unsaturated soil strength parameters. The Mohr yield criterion of Kulun Elastoplastic constitutive model is applied in this model, the different time of slope shear strain increment is shown in Fig. 5. 


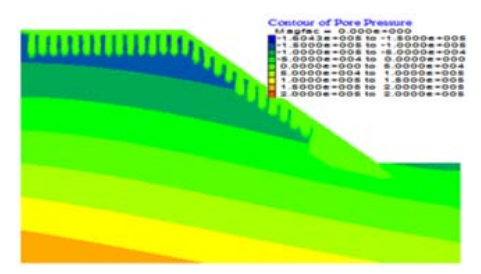

(a) 24 hours time

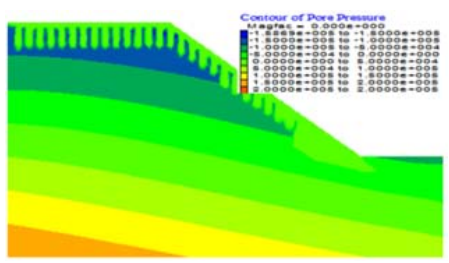

(b) 48 hours time.

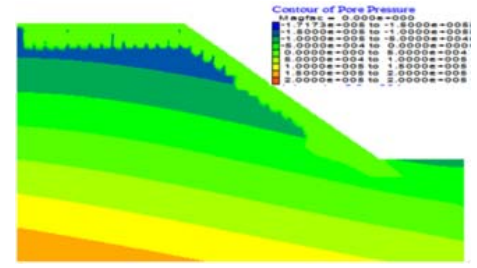

(c) 72 hours time (unit: $\mathrm{kPa}$ ).

Fig. 4. Contours of pore water pressure in different seepage moment

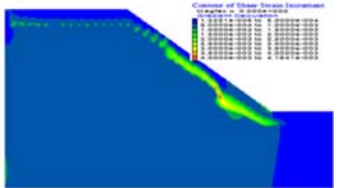

(a) 24 hours time

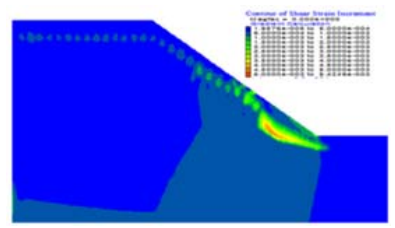

(b) 48 hours time.

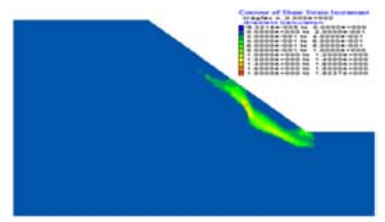

(c) 72 hours time (unit: $\mathrm{kPa}$ ).
As is shown, with the rainfall, the potential sliding surface of slope depth is gradually from deep shallow, cut to gradually develop. The shear strain increment gradually in the slope toe formed through the region, the potential sliding surface is formed at the bottom of slope, at the slope toe is easy to form the local landslide, and then drive the upper rock body formed tractive landslide, compared with the whole landslide, formation of the landslide is shallow, the characteristic of traction, the simulation results in accord with the characteristics of expansive soil slope landslide.

\section{CONCLUSION}

1) The existence of fissures is an important influence factor of expansive soil slope landslide under rainfall, the shallow slope occurred unsaturated to saturated after rainfall, transient saturated zone appear in slope top at initial stage, gradually extended to the foot of the slope, the pore water pressure field changed great influence by the distribution of fissures.

2) Expansive soil slope landslide is associated with rainfall and the soil softening under rainfall. In general, at the beginning, seepage of rainfall great effect the stability of eapansive soil slope, rainfall late and rain stopped the rock soil softening effect the slope stability apparent.

3) Fissures have a significant influence on the seepage field and intensifies the infiltration rate of rainfall, under the seepage and soil softening of expansive slope, potential sliding surface changed and transition to instability, fissures and soil softening accelerate this process.

\section{REFERENCES}

[1] S.W. Liao, "Expansive soil and railway subgrade engineering”, China Railway Publ. House. pp. 10-35, 1984.

[2] J.P. Yuan, and Z.Z. Yin, "Numerical model and simul ation of expansive soils slope infiltration considered fissures.” Rock. Soil. Mech. vol. 25, no. 10, pp. 1581-1586, 2004.

[3] B. Velde, "Structure of surfacefissures in soil and muds." Geoderma. vol. 93, no. 1/2, pp. 101-124, 1999.

[4] Z.Z. Yi, and B. Xu, "Slope stability of expansive soil under fissure influence.” Chinese J. Geotech. Eng. vol. 33, no. 3, pp. 454-459, 2011.

[5] R.J. Xiao, "Geologic hazard study of expensive soil in South Shanxi Province”, Xi'an: Shaanxi Sci. Tech. Press. pp. 27-42, 1995.

[6] D.F. Li, and H. Chen, "The relation between landslide and rainfall in Hong Kong.” Hydrogeology \& Engineering Geology. no. 4, pp. 34-38, 1997.

[7] X.M. Wu, "Stability of subgrade of expansive soil.” Railway Eng., no. 7, pp. 9-13, 1990

[8] T.H. Liu, "Problems of expansive soil in engineering”, China Architecture. Build. Press. pp. 3-11. 1997

Fig. 5. Contours of slope shear strain increment in different seepage moment 